\title{
NANOENCAPSULATION OF BIOACTIVE INGREDIENTS: TRENDS IN PHARMACEUTICAL INDUSTRY AND FUNCTIONAL FOODS
}

\author{
NANOENCAPSULACIÓN DE INGREDIENTES BIOACTIVOS: TENDENCIAS EN LA \\ INDUSTRIA FARMACÉUTICA Y EN ALIMENTOS FUNCIONALES
}

Multiple researches have allowed the development of nanoencapsulation techniques that ease the controlled or targeted release of bioactive components and favor their incorporation in different foods and medication formulations to improve their bioavailability $(1,2)$. Recent studies have facilitated the development of nanoencapsulation systems of different active ingredients for functional foods, comprising phenolic compounds, antioxidants, essential oils, minerals, flavors, fish oils, essential fatty acids, vitamins, antimicrobials, soluble fiber, peptides, lycopene, lutein, $\beta$-carotene, phytosterols, iron, calcium, among others $(3,4)$, as well as bioactive compounds for therapeutic applications as polyphenols, curcumin, quercetin, resveratrol and epigallocatechin-3-gallate (5).

It is considered that a nano sized system is the one constituted by particles with a size lesser than 1000 $\mathrm{nm}(3)$, despite some researchers consider that this concept is suitable when the particles size is lesser than $500 \mathrm{~nm}$ (6), while others that said concept is appropriate when $50 \%$ of the particles have a size lesser than $100 \mathrm{~nm}$ (7). Nanoencapsulation technologies use nano-vehicles, named nanocarriers, that facilitate the transportation of bioactive ingredients.

These nanocarriers present the following advantages: a) they improve the bioavailability of active components due to the increase of surface-to-volume ratio; b) they ease the interaction with metabolism and enzyme factors; c) they enhance of solubility of hydrophobic components in the site of action; d) allow the pass through cell walls; $f$ ) they favor the muco-adhesiveness of the small intestine and; e) they do not interfere with the appearance of the final product $(8,9)$.

There is great diversity of nanocarriers in the medium, which can be classified according to their composition or according to the method of obtainment, as follows (3):

1) Nanocarriers based on biopolymer particles obtained from: a) simple systems (protein nanoparticles obtained from desolvation of proteins, as lactoglubin, or polysaccharide nanoparticles obtained from precipitation, as chitosan and cellulose); b) nanogels in which are comprised nanohydrogels, nanoorganogels/oleogels and mixtures of gels obtained from chitosan, whey and soy proteins, and alginates; c) complex systems of biopolymer nanoparticles, as nanostructures of polysaccharide-polysaccharide, protein-protein and protein-polysaccharide and; d) nanotubes and nanofibers, which include nanotubes made with $\alpha$-lactoalbumin and nanofibers made with $\beta$-lactoalbumin (10-13).

2) Nanocarriers based on lipids, in which are fats or oils. Examples of these systems are: a) nanoemulsions $(\mathrm{O} / \mathrm{W}$ or $\mathrm{W} / \mathrm{O})$ or double nanoemulsions $(\mathrm{O} / \mathrm{W} / \mathrm{O}$ or $\mathrm{W} / \mathrm{O} / \mathrm{W})$; b) nanoliposomes prepared from oils, phospholipids and different solvents, suitable to incorporate hydrophilic and hydrophobic ingredients, given the features of their components; and c) the carriers of nanolipids, which are assumed to have better control of size and release process of the bioactive ingredients $(6,14)$.

3) Nanocarriers obtained through high technology equipment as electro-spinning and electro-spraying, nanofluidic systems and nano spray dryer (15-17).

4) Nanocarriers of natural origin, which are nanovehicles that exist in nature and have been used in encapsulating systems as amylose, casein and cyclodextrin nanostructures (18-20). 
5) Other types of nanocarriers comprise: a) nanocrystals (bioactive components with cellulose or starch nanocrystals, or bioactive crystals with other type of nanocarriers); b) nanostructured surfactants (microemulsions, niosomes, cubosomes); c) polymer nanoparticles (dendrimers, poly-capro-lactone (PCA); poly-gamma-glutamic (PGA) or poly-delta-L-lactide (PLA); d) inorganic nanocarriers (gold, silica or magnetic nanoparticles, carbon nanotubes, or quantic point). These types of nanocarriers have been used mostly in the pharmaceutical area (3).

With the arise of nanotechnology, it has been evidenced a range of possibilities related to design, formulation and development of products and medications with an innovator component. The usage of different nanoencapsulation techniques is an opportunity at disposal of foods and pharmaceutical industries to lead their efforts towards goods or medications with added value respect to other products offered in the market, given the improvements that these techniques provide to their features. This is, products with better properties that allow increasing the bioavailability and effectiveness of bioactive ingredients, as well as their sensorial quality.

DIANA MARGARITA MÁRQUEZ FERNÁNDEZ Química Farmacéutica, MSc, PhD, Profesora Asociada de Tiempo Completo, Facultad de Ciencias Farmacéuticas y Alimentarias, Universidad de Antioquia, Medellín, Colombia.

\section{REFERENCES}

1. Akhavan S, Assadpour E, Katouzian I, Jafari sm. Lipid nano scale cargos for the protection and delivery of food bioactive ingredients and nutraceuticals. Trends Food Sci Tech. 2018; 74:132-46. DOI: 10.1016/j.tifs.2018.02.001

2. Faridi Esfanjani A, Assadpour E, Jafari SM. Improving the bioavailability of phenolic compounds by loading them within lipid-based nanocarriers. Trends Food Sci Tech. 2018; 76:56-66. DOI: 10.1016/j.tifs.2018.04.002

3. Assadpour E, Jafari SM. (2018): A systematic review on nanoencapsulation of food bioactive ingredients and nutraceuticals by various nanocarriers. Crit Rev Food Sci Nutr. 2018; 1-47. DOI: 10.1080/10408398.2018.1484687

4. Shampa Sen, Yashwant V. Pathak. Nanotechnology in Nutraceuticals: Production to Consumption. Boca Ratón, Florida, United States: Taylor and Francis Group; 2017. 465p.

5. Conte R, Calarco A, Napoletano A, Valentino A, Margarucci S, Di Cristo F, Di Salle A, Peluso G. Polyphenols Nanoencapsulation for Therapeutic Applications. J Biomol Res Ther. 2016; 5:2. DOI: 10.4172/2167-7956.1000139

6. Solans C, Izquierdo P, Nolla J, Azemar N, García C. Nano-emulsions. Curr Opin Colloid Interface Sci. 2005 ; 10 (3-4):102-10. DOI:10.1016/j.cocis.2005.06.004

7. Juan Huang, Qiang Wang, Tong Li, Nan Xia, Qiang Xia. Nanostructured lipid carrier (NLC) as a strategy for encapsulation of quercetin and linseed oil: Preparation and in vitro characterization studies. J Food Eng. 2017; 215:1-12. DOI: 10.1016/j.jfoodeng.2017.07.002

8. Jafari SM, McClements DJ. 2017. Chapter One - Nanotechnology approaches for increasing nutrient bioavailability. In Advances in Food and Nutrition Research. 81:1-30. Cambridge, United States: Academic Press. 378p. DOI: 10.1016/bs.afnr.2016.12.008

9. McClements DJ, Jafari SM. 2018. Chapter 1 - General Aspects of nanoemulsions and their formulation. Nanoemulsions. Formulation, Applications, and Characterization. 3-20. DOI: 10.1016/B978-0-12-811838-2.00001-1

10. Mohtashamian S, Boddohi S. Nanostructured polysaccharide-based carriers for antimicrobial peptide delivery. J Pharm Investig. 2017; 47:85-94. DOI: 10.1007/s40005-016-0289-1

11. Ghasemi S, Jafari SM, Assadpour E, Khomeiri M. Nanoencapsulation of d-limonene within nanocarriers produced by pectin-whey protein complexes. Food Hydrocoll. 2018; 77:152-62. DOI: 10.1016/j.foodhyd.2017.09.030

12. Abaee AM Mohammadian, Jafari SM. Whey and soy protein-based hydrogels and nano-hydrogels as bioactive delivery systems. Trends Food Sci Tech. 2017; 70 (Supplement C): 69-81. DOI: 10.1016/j.tifs.2017.10.011

13. Jafari SM. 2017. 1 - An overview of nanoencapsulation techniques and their classification. In Nanoencapsulation technologies for the food and nutraceutical industries, 1-34. San Diego, United States: Academic Press. 636p. DOI: 10.1016/B978-0-12-809436-5.00001-X

14. Demirci M, Caglar MY, Cakir B, Gülseren I. 2017. 3 - Encapsulation by nanoliposomes A2 - Jafari, Seid Mahdi. In Nanoencapsulation technologies for the food and nutraceutical industries, 74-113. San Diego, United States: Academic Press. 636p. DOI: 10.1016/B978-012-809436-5.00003-3

15. Tapia-Hernández JA, Rodríguez-Felix F, Katouzian I. 2017. 9 - Nanocapsule formation by electrospraying A2 - Jafari, Seid Mahdi. In Nanoencapsulation technologies for the food and nutraceutical industries, 320-345. San Diego, United States: Academic Press. 636p. DOI: 10.1016/B978-0-12-809436-5.00009-4

16. Arpagaus C, John P, Collenberg A, Rutti D. 2017. 10 - Nanocapsules formation by nano spray drying A2 - Jafari, Seid Mahdi. In Nanoencapsulation technologies for the food and nutraceutical industries, 346-401. San Diego, United States: Academic Press. 636p. DOI: 10.1016/B978-0-12-809436-5.00010-0

17. Ran R, Sun Q, Baby T, Wibowo D, Middelberg APJ, Zhao C-X. Multiphase microfluidic synthesis of micro- and nanostructures for pharmaceutical applications. Chem Eng Sci. 2017; 169 (Supplement C):78-96. DOI: 10.1016/j.ces.2017.01.008

18. Jafari SM. 2017. Chapter 1 - An introduction to nanoencapsulation techniques for the food bioactive ingredients. In Nanoencapsulation of food bioactive ingredients, 1-62. London, United Kingdom: Academic Press. 500p. DOI: 10.1016/B978-0-12-809740-3.00001-5

19. Haratifar S, Guri A. 2017. 5 - Nanocapsule formation by caseins A2 - Jafari, Seid Mahdi. In Nanoencapsulation technologies for the food and nutraceutical industries, 140-164. San Diego, United States: Academic Press. 636p. DOI: 10.1016/B978-0-12-809436-5.00005-7

20. Gharibzahedi SMT, Jafari SM. 2017. 7 - Nanocapsule formation by cyclodextrins. In Nanoencapsulation technologies for the food and nutraceutical industries, 187-261. San Diego, United States: Academic Press. 636p. DOI: 10.1016/B978-0-12-809436-5.00007-0 